\title{
The pathogenesis of autism spectrum disorder
}

\author{
Beatriz Sanabria-Barradas, ${ }^{1,2}$, Libna S. Gallardo-Beatriz ${ }^{2,3}$, José A. Palma-Jacinto ${ }^{2,4}$, and \\ Ana L. Calderón-Garcidueñas ${ }^{5 *}$ \\ ${ }^{1}$ Laboratory of Psychobiology, Faculty of Psychology; ${ }^{2}$ Doctoral Program in Biomedical Sciences; ${ }^{3}$ Support Services Unit in Analytical Resolution; \\ ${ }^{4}$ Laboratory of Biochemistry and Neurotoxicology, Faculty of Bioanalysis; ${ }^{5}$ School of Medicine. Universidad Veracruzana, Veracruz, Mexico
}

\begin{abstract}
This manuscript reviews the mechanisms that contribute to the production of the autism spectrum disorder (ASD), especialIy the genetic and immunological components. Knowing the participating elements and mechanisms are essential to establish preventive measures and look for early markers. The ASD can have subtle or devastating manifestations, and exerting immunomodulatory actions could be useful in the management of these patients. There seems to be different environmental insults that may act as triggers in genetically predisposed subjects; these insults can promote an inflammatory response in which interleukin-6 could participate actively at the level of neural stem cells and progenitors. The degree of involvement in neurogenesis and astrogenesis, and therefore, the observed clinical spectrum will depend on two facts that alter the neural circuits, including the brain region that loses proper input or output connectivity due to abnormal migration of a group of neurons, and the astrocytic survival.
\end{abstract}

Key words: Autism. Pathogenesis. Risk factors. Immunology. Genetics.

\section{La patogenia del trastorno del espectro autista}

\section{Resumen}

Este manuscrito revisa los mecanismos que contribuyen a la producción del trastorno del espectro autista (TEA), especialmente los componentes genéticos e inmunológicos. Conocer los elementos y mecanismos participantes es fundamental para establecer medidas preventivas y buscar marcadores tempranos. EI TEA puede tener manifestaciones sutiles o devastadoras, y ejercer acciones inmunomoduladoras podría ser útil en el manejo de estos pacientes. Parece haber diferentes agresiones ambientales que pueden actuar como desencadenantes en sujetos genéticamente predispuestos; Estas agresiones pueden promover una respuesta inflamatoria en la que la interleucina-6 podría participar actuando activamente a nivel de células madre neurales y progenitores. El grado de implicación en la neurogénesis y la astrogénesis, y por tanto, el espectro clínico observado, dependerá de dos hechos que alteran los circuitos neuronales, incluida la región del cerebro que pierde la conectividad de entrada o salida adecuada debido a la migración anormal de un grupo de neuronas, y la supervivencia astrocítica.

Palabras clave: Autismo. Patogenia. Factores de riesgo. Inmunología. Genética.

\section{Correspondence:}

*Ana L. Calderón-Garcidueñas E-mail: acald911@ hotmail.com
Available online: 15-11-2021 Rev Mex Neuroci. 2021;22(6):248-255 www.revmexneurociencia.com 2604-6180/ @ 2021 Academia Mexicana de Neurología A.C. Published by Permanyer. This is an open access article under the CC BY-NC-ND license (http://creativecommons.org/licenses/by-nc-nd/4.0/). 


\section{Introduction}

The autism spectrum disorder (ASD) is a neurodevelopmental disorder characterized by repetitive, stereotypical behavior, deficiencies in communication and social interactions, including deficiencies in social reciprocity, in nonverbal communicative behaviors, and in the skills to develop, to maintain and understand social relationships ${ }^{1}$. Leo Kanner described autism in 1943; at that time, it was considered to affect 4-5/10,000 children; in 2011, the incidence was 1 per 110 children in the United States and one per 64 in the United Kingdom. At present, about 1, in 59 children under the age of eight, have been diagnosed with ASD according to the Developmental Disabilities Monitoring Network, and predominates in boys, with a ratio of $4: 1^{2}$. ASD is multifactorial: a mother and an embryo with genetic susceptibility, probably exposed to external triggers such as infections, toxins, environmental pollutants, and nutritional deficiencies, and/or to internal factors (autoimmune diseases) that condition an inflammatory state in which the microglia and numerous cytokines, especially interleukin 6 (IL-6), exert actions that negatively affect the structure and functionality of the developing brain. Knowing the participating elements is essential to establish preventive measures and look for early markers. The ASD can have subtle or devastating manifestations, and exerting immunomodulatory actions could be useful in the management of these patients. Therefore, our objective is to present a current overview of the pathogenesis of the ASD, specially focused on the genetic factor and the immune system, for which a review of the literature was carried out using the terms, pathogenesis, immunology, and genetics of ASD.

\section{Genetics}

The genetic factor is important. If one identical twin is affected, the other will present the problem in 36$95 \%$ of cases. In non-identical twins, the other is affected about $0-31 \%$ of the time. And parents who have a child with ASD have a $2-18 \%$ chance of having a second child, affected ${ }^{3}$. Neurodevelopment is influenced by innate and environmental factors that can modify synapse plasticity, brain structures, cognition, and behavior ${ }^{4}$. There is an interaction between multiple genes to give the autistic phenotype. Heritability in ASD is about 50 or $55 \%^{5}$. Genes related to neurodevelopment such as TEX 49 (LINC00935) and CCNT1 are implicated in ASD and in reading disabilities ${ }^{6}$. Furthermore, genes that code for proteins related to the immune system are involved. It is important to have a general idea of the genes involved in autism, since, as will be seen later, in embryonic processes, the participation of cells of the immune system is important for tissue molding. A large exome sequencing study showed 102 genes involved in risk for ASD. Most of them are expressed in excitatory and inhibitory neuronal lineages, affect synapses, regulate other genes or are related to the immune system?

\section{HLA system}

The DR4 allele of the MHC is one of the susceptibility markers for certain autoimmune diseases, such as rheumatoid arthritis, hypothyroidism, and autoimmune diabetes. Compared to controls, children with ASD had significantly increased numbers of $\mathrm{HLA}-\mathrm{DR}{ }^{+} \mathrm{CD} 4^{+}$,

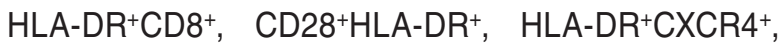
and $\mathrm{HLA}-\mathrm{DR}{ }^{+} \mathrm{CCR} 7^{+}$cells ${ }^{8}$. Boys with ASD and their mothers have a higher frequency of DR4 than subjects with normal development ${ }^{8}$. Increased relative risk for autism has been observed with HLA hypervariable region 3 of $D R B 1^{*} 0401$ in children from North America and China ${ }^{9}$. Furthermore, ASD children have increased frequency of the null allele of the $C 4 B$ gene. This gene encodes the basic form of complement factor 4 , part of the classical activation pathway and is located in the major histocompatibility complex (MHC) Class III region, on chromosome $6^{10}$.

\section{RELN gene}

The RELN gene codifies a protein called reelin that activates a signaling pathway that triggers neurons to migrate to their proper locations. After birth, reelin participates in the extension of axons and dendrites, the regulation of synaptic plasticity, and the release of neurotransmitters. The homozygous mutations lead to brain hypoplasia, developmental delay, and epilepsy. However, heterozygous mutations in RELN are related with the ASD ${ }^{11}$.

\section{SHANK3 gene}

It encodes a protein that acts as a scaffold that supports the connections between neurons, ensuring communication between them; the protein participates in the formation and maturation of dendritic spines. Alterations in this gene, including the 22q13.3 deletion, appear to be related to ASD. Lymphoblasts of individuals with ASD show reduced expression of this gene ${ }^{12}$. 


\section{MET gene}

MET gene encodes a member of the receptor tyrosine kinase family of proteins. When this receptor binds to the hepatocyte growth factor, it dimerizes and has a role in cellular survival, embryogenesis, and cellular migration and invasion. In the human brain, this gene is highly expressed in temporal, occipital, and medial portions of the parietal lobes. At least, two common risk alleles have been identified. Postmortem analysis of temporal cortex of ASD patients showed $50 \%$ reduced levels of MET protein in the superior temporal gyrus. MET signaling has a role not only in neocortical and cerebellar growth and maturation, but also in gastrointestinal repair, and immunological competence, functions that have been reported as abnormal in children with autism ${ }^{13}$.

\section{CNTNAP2 gene}

The CNTNAP2 gene (contactin associated protein 2), located in chromosome 7q35-q36.1, encodes a member of the neurexin family which functions as cell adhesion molecule and receptor in the central nervous system (CNS). It is also involved in localization of potassium channels within differentiating axons. FOXP2 encodes a transcription factor involved in the regulation of numerous genes, including CNTNAP2. Both genes have been related to autism and language disorders although some authors have not confirmed these findings $^{14}$. On the other hand, FOXP1 gene has elevated expression in ASD subjects and functions as a transcription repressor, forming a heterodimer with FOXP2 ${ }^{14}$.

\section{SLC6A4 gene (5-HTTLPR gene)}

Solute carrier family 6 , member 4 gene, encodes a membrane protein that transports serotonin from synaptic spaces into presynaptic neurons. Autism patients have shown linkage/association with $S / L$ alleles of 5- HTTLPR locus, with over transmission of $S$ alleles. In animal models, mothers under prenatal stress having the low activity allele had an increased risk for autism-like characteristics in the offspring ${ }^{15}$.

\section{Activation of the immune system}

Nervous and immune systems are in constant communication. Reactive antibodies have been isolated from the CNS and there is evidence of intraplacental transmission of mother to fetus antibodies resulting in
ASD. There appears to be an immune dysfunction in ASD; inflammatory mediators, including serum and brain antibodies, inflammatory serum cytokines, chemokines, and adhesion molecules have been documented. Autoimmune phenomena such as hyperactivity of monocytes, rapid responses of NK, decrease of both, regulatory cells, and IL-10 production have also been found ${ }^{16}$.

\section{Cells of the immune system}

\section{Phagocytic cells/Microglia}

The microglia cells located in CNS cell, when activated, become macrophages. It is known that androgen-induced increases in endocannabinoid tone, promote microglia phagocytosis during a critical period of amygdala development. Phagocytic microglia engulfs more viable astrocytic newborn cells in males; in females, less phagocytosis allows more astrocytes to survive to the juvenile age ${ }^{17}$. Therefore, microglia have an important role in neurodevelopment and ASD is precisely, a neurodevelopmental disorder. Microglial cells responds to type-2 alarmin, and to IL-33, derived from astrocytes, to promote synaptic pruning in the reticular thalamic nucleus, as well as the hippocampus $^{18}$. Microglia are able to regulate programmed neuronal death, participate in promotion of synaptogenesis, and strip excess synapses from developing neurons allowing the integration of functional neuronal circuits. Deficits in synaptic pruning play a role in ASD where either hyperconnectivity and/or hypoconnectivity are observed across the amygdala, pre-frontal cortex, and components of the default-mode network ${ }^{19}$.

\section{$T$ cells}

Th17, Th1, Th2, and Th regulatory $\left(\mathrm{T}_{\text {reg }}\right)$ cells participate in the progress and development of neurological disorders. $T_{\text {reg }}$ cells prevent the development of immune diseases and inhibit self-reactivity. Children with ASD have significantly fewer $T_{\text {reg }}$ cells, but also a larger number of activated Th17 and myeloid dendritic cells (mDCs) compared to children without autism. There is an imbalance in the $T h 17 / \mathrm{T}_{\text {reg }}$ relationship with marked deviation towards Th17; furthermore, the number of Th17 cells correlates positively with the severity of the disease, while $T_{\text {reg }}$ cells have a negative correlation $^{20}$. Signal transducer and activator of transcription 3 (STAT3) and GATA-3 pathways appear to be primarily involved. Th17 is regulated by the translocation of STAT 
to the nucleus where it promotes the transcription of related orphan receptor gamma (RORyt); the regulation of mRNA and expression of STAT3 are increased in patients with $A S D^{20}$. In murine models, activation of nuclear factor erythroid 2 related factor (Nrf2) ameliorated autism-like symptoms through suppression of Th17 related signaling and rectification of oxidant-antioxidant imbalance in both, periphery, and brain. The transcription factor Nrf2 is related to antioxidant and anti-inflammatory genes; sulforaphane is an activator of Nrf2. In mice, the treatment with sulforaphane corrected Th17 immune dysfunction and oxidant-antioxidant imbalance in neutrophils and cerebellum ${ }^{21}$.

Forkhead Box P3 (Foxp3) is the most important transcription factor in the proliferation and function of $\mathrm{T}_{\text {reg }}$ lymphocytes. Foxp3 is also expressed in glial cells and inhibits inflammation-induced neuronal excitability by attenuation of TLR4 signaling and inflammation; $T_{\text {reg }}$ cell suppresses pro-inflammatory $T$ cell responses directed against "self" antigens and favors the resolution of immune responses that can harm the body. In fact, the genetic variant rs2232365 is associated with ASD in dominant inheritance model ${ }^{22}$.

T cell immunoglobulin and mucin domain-3 (TIM-3) or T helper (Th)-specific type I membrane protein, and its ligand, galectin-9 have an important role in Th1 immunity and tolerance induction because downregulate Th1 responses. TIM-3 has regulatory functions extended to Th17 cells, CD4 (+) CD25 (+) Treg, CD8 (+) $T$ cells, and certain innate immune cells. In fact, Increased numbers of $\mathrm{CD} 3^{+} \mathrm{TIM}-3^{+}, \mathrm{CD} 4^{+} \mathrm{TIM}-3^{+}, \mathrm{CD} 8^{+-}$

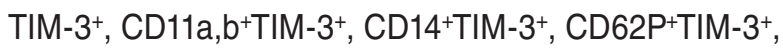
and $\mathrm{CXCR} 5^{+} \mathrm{TIM}^{-} 3^{+}$cells have been documented in children with ASD as compared with controls. These children also have increased production of IL-1 $\beta^{+} \mathrm{TIM}-3^{+}$, IFN- $\gamma^{+} \mathrm{TIM}-3^{+}$, and IL-17+ $17^{+} \mathrm{IM}-3^{+}$, and decreased production of Foxp3 $3^{+} \mathrm{TIM}^{-3^{+}}$compared with controls. In this way, TIM3 could be considered as an early marker of $\mathrm{ASD}^{23}$. In the other hand, histopathological and immunohistochemical studies in the ASD brains have shown perivascular cuffs of predominantly CD3+T lymphocytes with less proportion of $\mathrm{CD} 2 \mathrm{O}^{+} \mathrm{B}$ lymphocytes and $\mathrm{CD}^{+}$over $\mathrm{CD}^{+} \mathrm{T}$ lymphocytes. The number of lymphocytes in those cuffs correlates with the quantity of astrocyte-derived round membranous blebs. Membranous blebs are cytotoxic reaction to lymphocyte attack and produce damage to the BBB with increased vascular permeability at the at periventricular white matter, and in the subpial region of the cerebral corte ${ }^{24}$.

\section{$B$ cells}

A systemic mitochondrial dysfunction has been reported in ASD and a subset of ASD patients could have a genetic predisposition to mitochondrial/antioxidant insults; B-lymphocytes in these patients show less growth suppression and less mitochondrial proliferation when exposed to dichlorodiphenyldichloroethylene, estradiol, and dihydrotestosterone ${ }^{25}$. In addition, CT genotype in rs10001565 of CD157/BST1 gene, also referred to as bone marrow stromal cell antigen-1 (BST-1) confers susceptibility to ASDs, at least in Japanese patients. CD157 is a glycosylphosphatidylinositol-anchored molecule that promotes pre-B-cell growth ${ }^{26}$.

\section{Natural killer cells (NK)}

NK cells are innate lymphocytes activated by infected cells, foreign cells, and neoplastic cells. Many patients with autism have a reduction of a mature lymphocyte subpopulation of natural killer cells CD57(+)CD3(-). $\mathrm{CD}^{2} 7^{+} \mathrm{NK}$ cells differentiate from CD56 ${ }^{\mathrm{dim}} \mathrm{CD} 57^{-}$; acquisition of CD57 represents a shift toward a higher cytotoxic capacity. Reduced number of circulating CD57 ${ }^{+}$NK cells and/or impaired NK cell cytotoxicity is associated with autoimmune disease, suggesting that cytotoxic $\mathrm{CD} 57^{+} \mathrm{NK}$ cells may play a regulatory role, preventing, or suppressing autoimmune disease (AD). $A$ high frequency of $A D$ in children with autism has been described ${ }^{27}$.

In high-functioning ASD adult patients, a high level of NK cell activation has been observed with spontaneous degranulation and interferon-gamma production when compared with healthy controls, whereas these cells become exhausted after in vitro stimulations ${ }^{28}$. The profile HLA-DR+KIR2DL1+NKG2C+ NK-cell was observed in ASD patients. This overexpression of NKG2C is indicative of viral infections, and it was inversely correlated with the NKp46 receptor level ${ }^{28}$. On the other hand, NK cells are activated by the interaction between killer-cell immune globulin-like receptor (KIR) and the HLA ligands. Class I alleles (HLA-A2 and HLA-G 14 bp-indel) and three activating KIR genes: 3DS1, 2DS1, and 2DS2 have increased frequencies in autism populations ${ }^{29}$.

\section{Dendritic cells}

Dendritic cells are antigen-presenting cells; children with ASD have significantly higher percentages of $\mathrm{mDCs}$ and plasmacytoid dendritic cells (pDCs) than 
controls. Amygdala volume and repetitive behavior in children with ASD are related to the increase in the frequency of $\mathrm{mDCs}^{30}$.

\section{Mast cells}

In children, ASD and atopy have increased in incidence in recent years. Mast cells participate in type I hypersensitivity reactions; stress and environmental stimuli activate mast cells, to produce immunomodulators that alter the functionality of BBB and cause microglia activation, leading to abnormal synaptic pruning and dysfunctional neuronal connectivity, that in combination with the corticotropin-releasing hormone secreted under stress, may contribute to the pathogenesis of $A S D^{31}$.

\section{Humoral components}

The relationship between the immune system and the nervous system is complex; there are cytokines that directly affect the function and development of neural tissue, for example, IL 1, 6, and 12. In addition, immune dysfunctions in this disease lead to the generation of antibodies.

\section{Cytokines}

An imbalance of Th1- Th2 cytokines in the cerebrospinal fluid (CSF) of children with ASD has been demonstrated. Furthermore, lower concentration of anti-inflammatory cytokines IL-10 and IL-1Ra ${ }^{32}$, and higher plasma levels of IL-1 $\beta$, IL- 6, IL- 8 , and IL-12p40 have been observed in ASD patients compared to controls ${ }^{33}$. Some ASD children show excessive innate immune responses with higher concentration of TNF- $\alpha$ in plasma and CSF compared to controls ${ }^{34}$. In murine models, maternal immune activation induced by pathogens during pregnancy changed the cytokine expression profile in maternal and fetal organs and correlated with TNF $\alpha$ and IL-18 dysregulation ${ }^{35}$. In addition, cortical neurons of frontal and temporal lobes involved in learning and memory are more susceptible to cytokine-induced inflammation through the NF- $\mathrm{kB}$ signaling pathway. There is evidence of aberrant expression of NF-KB in the orbitofrontal cortex in autopsy material in humans ${ }^{36}$. In mice models, high levels of IL-6 in the brain are related to alterations in excitatory and inhibitory synaptic formations and to abnormal dendritic spines in the cerebellum; IL-6 over-expression promoted the formation of granule cell excitatory synapses, without affecting inhibitory synapses ${ }^{37}$. High levels of IL-6 have been documented in maternal serum and amniotic fluid of children that later on, developed autism. In animal models, it was found that circulating IL-6 levels, two-fold above baseline, increased the platelet-derived growth factor (PDGF)-responsive multipotent progenitor, the phosphorylated STAT3, and the Fbxo15 expression, and decreased Dnmt1 and TIx expression; the evident consequence was decreased astrogliogenesis in the frontal cortex, proving that inflammation is able to alter neural stem cells and progenitors $^{37}$

\section{Antibodies}

Maternal autoimmunity is a risk factor for having a child with autism (rheumatoid arthritis, celiac disease, psoriasis, systemic lupus erythematosus, and autoimmune thyroid disease); also, a family history of type I diabetes increases the risk. Children born to mothers with autoimmune disease are $34 \%$ more likely to develop $\mathrm{ASD}^{38}$. During critical windows of fetal life, maternal immune response has a long-lasting impact on neurodevelopment. Mothers with autoantibodies to the 37 and $73 \mathrm{kDa}$ fetal brain bands (found only in ASD) have in $95 \%$ of the cases, a functional variant in the $5^{\prime}$ promoter of the gene encoding the MET receptor tyrosine kinase. The MET promoter variant, rs1858830MET is a G-to-C single-nucleotide polymorphism (SNP) called the ' $C$ ' allele that confers susceptibility for the production of those autoantibodies. Furthermore, this allelic variant is associated with decreased levels of IL-10, a crucial anti-inflammatory cytokine ${ }^{39}$. Antibodies to the 37 and $73 \mathrm{kDa}$ fetal brain bands recognize several developmentally regulated proteins in the fetal brain. These proteins are lactate dehydrogenase $A$ and $B$; stress-induced phosphoprotein 1 , that in combination with cellular prion protein participate in neuritogenesis and neuronal survival; Guanine Deaminase (GDA) with an important role in dendritic branching of hippocampal neurons; collapsin response mediator proteins 1 and 2 that are required for proper growth cone collapse and adequate cell migration and axon-dendrite specification: and Y-box binding protein 1(YBX1). These antibodies are associated with lower adaptive and cognitive function as well as core behaviors associated with autism ${ }^{40}$.

\section{Allergic reactions}

Mostafa et al. observed allergic manifestations (bronchial asthma, atopic dermatitis, and/or allergic rhinitis) 
in $52 \%$ of autistic patients, significantly higher than in controls $^{41}$. Some children with ASD have gluten and casein intolerance. IgE-mediated allergic diseases can aggravate behavioral symptoms and may be under-diagnosed in part due to the impaired communication skills of these children. Allergy is associated with activation of mast cells, innate lymphoid cells, and Th2 cells, and production of type-2 cytokines (IL4 and IL13), which favor the M2A phenotype in microglia and macrophages. These cells produce brain-derived neurotrophic factor (BDNF) and insulin-like growth factor-1. In neurons, these growth factors activate the enzyme mammalian Target of Rapamycin (mTOR), and inhibit autophagy. Redundant synapses are removed by autophagy ${ }^{42}$.

\section{Neuroinflammation and brain alterations}

As mentioned, pro-inflammatory cytokines profile (NF- $\kappa B$, TNF - $\alpha$, IFN- $\gamma$, MCP-1, TGF- $\beta 1$, IL-6, IL- $1 \beta$, and $\mathrm{IL}-17)$ is a key component of autism ${ }^{16}$. Furthermore, there is evidence of structural changes in the CNS of individuals with autism. Head circumference is significantly larger in autistic patients compared to control individuals, and around $16 \%$ of autistic individuals had macrocephaly ${ }^{43}$. Several studies have shown cortical abnormalities like dysplasia and heterotopia, as well as reduced neuronal, and cytoplasmic volumes in the majority of examined areas compared to age-matched controls; also, thickening in the subependymal layer and significant increase in neuropil, in the frontopolar region and the anterior cingulate; slower pruning of spines in the temporal lobe with greater spine density in adolescence has been shown. Other alterations include: abnormal persistence of vascular remodeling in the superior temporal cortex; increased diffuse density of microglia; abnormal overgrowth of neurons in prefrontal cortex; significantly smaller pyramidal neurons in the inferior frontal cortex, and alterations at the cellular level in specific areas of the brain that are associated with ASD behaviors, such as fusiform gyrus, frontoinsular and cingulate cortex, hippocampus, amygdala, cerebellum, and brainstem ${ }^{44}$. Controlled neuroinflammation plays a role in the normal development and maintenance of the dendritic spines involved in glutamatergic and GABAergic neurotransmission, and also influences blood-brain permeability. Cytokines released from microglia can impact the length, location or organization of dendritic spines on excitatory and inhibitory cells as well as recruit and impact glial cell function around the neurons. However, uncontrolled, dysfunctional neuroinflammation may have negative effects on brain development. It seems that the symptoms of ASD are the consequence of abnormal circuit wiring during embryonic development ${ }^{45}$.

\section{Gestational influence}

Gestation is a state of risk for the mother and the product. Bacteria and viruses are able to produce an immune-inflammatory response during pregnancy that could be a risk factor for neurodevelopmental disorders including ASD and schizophrenia; pro-inflammatory cytokines are able to cross the placenta and cause damage in the CNS. Mice studies suggest that Th17 cells (ROR $\gamma$ t-expressing) and IL-17 are required in the maternal immune activation (MIA) model for induction of ASD-like phenotypes in offspring. In MIA offspring, abnormal expression of TNF $\alpha$, and a reduction in the expression of the synaptic organizing proteins cerebellin-1 and GluR $\delta 2$ have been described. Alteration in synaptic proteins is associated with a deficit in the ability of Purkinje cells to form synapses; in these models, male offspring is more affected $^{20}$. In a murine-model, early dietary supplementation with Vitamin D, due to its immunomodulatory and neuroprotective effects, was able to mitigate or prevent neurodevelopmental disorders following maternal inflammation ${ }^{46}$.

\section{Intestinal microbiota}

There is a microbiota-gut-brain axis. Microbiota are able to influence on brain function via microglial-induced synaptic pruning. The newborn has an immature brain and to have the right intestinal flora at early postnatal stages is very important. There is a dysbiosis in ASD children, which may influence the development and severity of ASD symptomatology. The microbiota of these children are composed of the phyla Bacteroidetes, Firmicutes, and Actinobacteria. Among Egyptian children, those with ASD had two types of Clostridium (Clostridium diffiicile and Clostridium clostridiioforme) not found in neurotypical children, whereas neurotypical children yielded only one species (Clostridium tertium) not found in the ASD children ${ }^{47}$. The metagenome is the set of microbial genes present in a given environment or ecosystem. Investigations of both, metagenome and the effect of the microbiota on the functionality of the nervous system are ongoing. 


\section{Associated pathogens}

Influenza viruses, herpes simplex virus and rubella, urinary tract bacteria, and toxoplasma have been linked to the development of ASD. Human endogenous retroviruses (HERVs) are assumed to be remnants of retroviruses infections resulting from ancestral infections that were integrated into the genome and transmitted to offspring. These HERVs respond to external stimuli and can somehow modulate the immune response if they are located in strategic places; in fact, high expression levels of HERV-H in blood of autistic patients have been demonstrated ${ }^{48}$.

\section{Vaccination}

A Nationwide Cohort Study in Denmark found no significant difference between vaccinated (Measles, Mumps, Rubella) and unvaccinated children in relation to the frequency of autism ${ }^{49}$.

\section{Discussion}

ASD is a multifactorial pathology, characterized by dysregulation of various components, including gene expression and the immune system. It is important to recognize which genes are involved in the disorder and how their altered expressions contribute to the problem. Alterations in immune responses mediated by cytokines, pro-inflammatory factors, and the cellular component, have been associated with neurodevelopmental disruption. Allergies, maternal immune activation, viral infections, and exposure to toxic substances converge in the inflammatory process. The marked increase in the incidence of autism in the last decades is probably related to environmental phenomena that deregulate a precisely controlled inflammatory process throughout fetal neurodevelopment, conditioning permanent changes in the structure of CNS. Inflammation is capable of altering neural stem cells and progenitors, thereby altering neurodevelopment and the proper functioning of neural circuits. A critical situation with ASD is that although several pathophysiological mechanisms involved are known, there are very few that can be targeted by drugs. Therefore, therapeutic efforts have focused on the reestablishment of the excitatory/inhibitory balance described in this pathological spectrum. Besides glutamate and GABA receptors, serotonergic, oxytocinergic, dopaminergic, and cannabinoid systems have been implicated in autism, and more recently, $G$ protein-coupled receptor heteromers have been described (mGlu2-5HT2A, mGlu5-D2-A2A, D2-OXT, CB1-D2, D2-5HT2A, D1-D2, D2-D3, and OXT-5HT2A) ${ }^{50}$. There is still a long way to go in the therapeutic research of ASD.

\section{Conclusion}

Several environmental insults may act as triggers in genetically predisposed subjects; these insults can promote an inflammatory response in which IL-6 could participate acting at the level of neural stem cells and progenitors. The moment of appearance of the insult and its intensity will determine the degree of damage to neurogenesis and astrogenesis and to neuronal circuits and therefore, the clinical spectrum of the disease.

\section{Funding}

This research has not received any specific grant from agencies in the public, commercial, or non-profit sectors.

\section{Conflicts of interest}

None.

\section{Acknowledgments}

To the Consejo Nacional de Ciencia y Tecnología (CONACYT) that has contributed with the PhD Scholarships No. 717999,782401, and 931891 to SBB, GBLS, and PJJA.

\section{Ethical disclosures}

Protection of human and animal subjects. The authors declare that no experiments were performed on humans or animals for this study.

Confidentiality of data. The authors declare that no patient data appear in this article.

Right to privacy and informed consent. The authors declare that no patient data appear in this article.

\section{References}

1. American Psychiatric Association. Diagnostic and Statistical Manual of Mental Disorders (DSM-5). $5^{\text {th }}$ ed. Arlington, VA: American Psychiatric Publishing, Inc.; 2014.

2. Baio J, Wiggins L, Christensen DL, Maenner MJ, Daniels J, Warren Z, et al. Prevalence of autism spectrum disorder among children aged 8 years-Autism and developmental disabilities monitoring network, 11 sites, United States. MMWR Surveill Summ. 2018;67:1-23.

3. Kates WR, Burnette CP, Eliez S, Strunge LA, Kaplan D, Landa R, et al. Neuroanatomic variation in monozygotic twins pairs discordant for the narrow phenotype for autism. Am J Psychiatry. 2004;161:539-46. 
4. Theoharides TC, Kavalioti M, Martinotti R. Factors adversely influencing neurodevelopment. J Biol Regul Homeost Agents. 2019;33:1663-7.

5. Colvert E, Tick B, McEwen F, Stewart C, Curran SR, Woodhouse E, et al. Heritability of autism spectrum disorder in a UK population-based twin sample. JAMA Psychiatry. 2015;72:415-23.

6. Price KM, Wigg KG, Feng Y, Blokland K, Wilkinson M, He G, et al. Genome-wide association study of word reading: overlap with risk genes for neurodevelopmental disorders. Genes Brain Behav. 2020;19:e12648.

7. Satterstrom FK, Kosmicki JA, Wang J, Breen MS, De Rubeis S, An JY, et al. Large-scale exome sequencing study implicates both developmental and functional changes in the neurobiology of autism. Cell. 2020;180:568-84.e23

8. Ahmad SF, Ansari MA, Nadeem A, Bakheet SA, Al-Ayadhi, Alotaibi MR et al. Dysregulation of the expression of HLA-DR, costimulatory molecule, and chemokine receptors on immune cells in children with autism. Int Immunopharmacol. 2018;65:360-5.

9. Chien YL, Wu YY, Chen CH, Gau SS, Huang YS, Chien WH, et al. Association of HLA-DRB1 alleles and neuropsychological function in autism. Psychiatric Genet. 2012;22:46-9.

10. Mostafa GA, Shehab AA. The link of C4B null allele to autism and to a family history of autoimmunity in Egyptian autistic children. J Neuroimmunol. 2010;223:115-9.

11. Lammert DB, Howell BW. RELN mutations in autism spectrum disorder. Front Cell Neurosci. 2016;10:1-9.

12. Yi F, Danko T, Calado S, Patzke C, Park C, Wernig M, et al. Autism-associated SHANK3 haploinsufficiency causes Ih channelopathy in human neurons. Science. 2016;352:1-10.

13. Rudie JD, Hernandez LM, Brown JA, Beck-Pancer D, Colich NL, Gorrindo $\mathrm{P}$, et al. Autism-associated promoter variant in MET impacts functional and structural brain networks. Neuron. 2012;75:904-15.

14. Toma C, Hervás A, Torrico B, Balmaña N, Salgado M, Maristany M, et al Analysis of two language-related genes in autism: a case-control association study of FOXP2 and CNTNAP2. Psychiatr Genet. 2013;23:82-5.

15. Sjaarda CP, Hecht P, McNaughton AJ, Zhou A, Hudson ML, Will MJ et al. Interplay between maternal Slc6a4 mutation and prenatal stress: a possible mechanism for autistic behavior development. Sci Rep. 2017 ; 7:8735.

16. Hughes HK, Mills Ko E, Rose D, Ashwood P. Immune dysfunction and autoimmunity as pathological mechanisms in autism spectrum disorders. Front Cell Neurosci. 2018;13:405.

17. Smith CJ, Bilbo SD. Microglia sculpt sex differences in social behavior Neuron. 2019:102:275-7.

18. De Biase LM, Schuebel KE, Fusfeld ZH, Jair K, Hawes IA, Cimbro R et al. Local cues establish and maintain region-specific phenotypes of basal ganglia microglia. Neuron. 2017;95:341-56.

19. Cowan M, Petri W. Microglia: immune regulators of neurodevelopment. Front Immunol. 2018;9:1-8.

20. Moaaz M, Youssry S, Elfatatry A, El Rahman MA. Th17/Treg cells imbalance and their related cytokines (IL-17, IL-10 and TGF- $\beta$ ) in children with autism spectrum disorder. J Neuroimmunol. 2019;337:577071.

21. Nadeem A, Ahmad SF, Al-Harbi NO, Attia SM, Bakheet SA, Ibrahim KE, et al. Nrf2 activator, sulforaphane ameliorates autism-like symptoms through suppression of Th17 related signaling and rectification of oxidant-antioxidant imbalance in periphery and brain of BTBR $T+t f / J$ mice. Behav Brain Res. 2019;364:213-24.

22. Safari MR, Ghafouri-Fard S, Noroozi R, Sayad A, Omrani MD, Komasi A et al. FOXP3 gene variations and susceptibility to autism: a case-contro study. Gene. 2017;596:119-22

23. Ahmad SF, Ansari MA, Nadeem A, Bakheet SA, Al-Ayadhi, Alotaibi MR, et al. Dysregulation of $T$ cell immunoglobulin and mucin domain 3 (TIM3) signaling in peripheral immune cells is associated with immune dysfunction in autistic children. Mol Neurobiol. 2019;54:4390-400.

24. DiStasio MM, Nagakura I, Nadler MJ, Anderson MP. T Iymphocytes and cytotoxic astrocyte blebs correlate across autism brains. Ann Neurol. 2019;86:885-98

25. Rose S, Niyazov DM, Rossignol DA, Goldenthal M, Kahler SG, Frye RE. Clinical and molecular characteristics of mitochondrial dysfunction in autism spectrum disorder. Mol Diagn Ther. 2018;22:571-93.

26. Yokoyama S, Mahmuda N, Munesue T, Hayashi K, Yagi K, Yamagishi M, et al. Association study between the CD157/BST1 gene and autism spectrum disorders in a Japanese population. Brain Sci. 2015;5:188-200.

27. Siniscalco D, Mijatovic T, Bossmans E, Cirillo A, Kruzliak P, Lombardi VC, et al. Decreased numbers of CD57+ CD3- cells identify potential innate immune differences in patients with autism spectrum disorder. In Vivo. 2016;30:83-90.
28. Bennabi M, Tarantino N, Gaman A, Scheid I, Krishnamoorthy R, Debré P et al. Persistence of dysfunctional natural killer cells in adults with high-functioning autism spectrum disorders: stigma/consequence of unresolved early infectious events? Mol Autism. 2019;15:10-22.

29. Torres AR, Sweeten TL, Johnson RC, Odell D, Westover JB, Bray-Ward P, et al. Common genetic variants found in HLA and KIR immune genes in autism spectrum disorder. Front Neurosci. 2016;10:463.

30. Breece E, Paciotti B, Nordahl CW, Ozonoff S, Van de Water JA, Rogers, et al. Myeloid dendritic cells frequencies are increased in children with autism spectrum disorder and associated with amygdala volume and repetitive behaviors. Brain, behav Immun. 2012;31:69-75.

31. Theoharides TC, Kavalioti M, Tsilioni I. Mast cells, stress, fear and autism spectrum disorder. Int J Mol Sci. 2019;20:3611.

32. Saghazadeh A, Ataeinia B, Keynejad K, Abdolalizadeh A, Hirbod-Mobarakeh $\mathrm{A}$, Rezaei $\mathrm{N}$. Anti-inflammatory cytokines in autism spectrum disorders: a systematic review and meta-analysis. Cytokine. 2019; 123:154740.

33. Ashwood P, Krakowiak P, Hertz-Picciotto I, Hansen R, Pessah I, Van de Water J. Elevated plasma cytokines in autism spectrum disorders provide evidence of immune dysfunction and are associated with impaired behavioral outcome. Brain Behav Immun. 2011;25:40-5.

34. Guloksuz SA, Abali O, Cetin EA, Gazioglu SB, Deniz G, Yildirim A, et al. Elevated plasma concentrations of $S 100$ calcium-binding protein $B$ and tumor necrosis factor alpha in children with autism spectrum disorders. Braz J Psychiatry. 2017;39:195-200.

35. Garcia-Valtanen $P$, van Diermen BA, Lakhan N, Lousberg EL, Robertson SA, Hayball JD, et al. Maternal host responses to poly (I: C) during pregnancy leads to both dysfunctional immune profiles and altered behaviour in the offspring. Am J Reprod Immunol. 2020;84:e13260.

36. Young AM, Chakrabarti B, Roberts D, Lai MC, Suckling J, Baron-Cohen S. From molecules to neural morphology: understanding neuroinflammation in autism spectrum condition. Mol Autism. 2016;7:1-8.

37. Kumari E, Velloso FJ, Nasuhidehnavi A, Somasundaram A, Savanur VH, Buono KD. Developmental IL-6 exposure favors production of PDGF-responsive multipotential progenitors at the expense of neural stem cells and other progenitors. Stem Cell Reports. 2020;14:861-75.

38. Chen SW, Zhong XS, Jiang LN, Zheng XY, Xiong YQ, Ma SJ, et al. Maternal autoimmune diseases and the risk of autism spectrum disorders in offspring: a systematic review and meta-analysis. Behav Brain Res. 2016;296:61-9.

39. Heuer L, Braunschweig D, Ashwood P, Van de Water J, Campbell DB. Association of a MET genetic variant with autism-associated maternal autoantibodies to fetal brain proteins and cytokine expression. Transl Psychiatry. 2011;1:1-7.

40. Goines P, Haapanen L, Boyce R, Duncanson P, Braunschweig D, Delwiche $\mathrm{L}$. Autoantibodies to cerebellum in children with autism associate with behavior. Brain Behav Immun. 2011;25:514-23.

41. Mostafa GA, Hamza RT, El-Shahawi HH. Allergic manifestations in autistic children: relation to disease severity. J Pediatr Neurol. 2008:6:115-23.

42. Kalkman HO, Feuerbach D. Microglia M2A polarization as potential link between food allergy and autism spectrum disorders. Pharmaceuticals (Basel). 2017;10:95

43. Sacco R, Gabriele S, Persico AM. Head circumference and brain size in autism spectrum disorder: a systematic review and meta-analysis. Psychiatry Res. 2015;234:239-51.

44. Varghese M, Keshav N, Jacot-Descombes S, Warda T, Wicinski B, Dickstein DL, et al. Autism spectrum disorder: neuropathology and animal models. Acta Neuropathol. 2017;134:537-66.

45. Pan YH, Wu N, Yuan XB. Toward a better understanding of neuronal migration deficits in autism spectrum disorders. Front Cell Dev Biol. 2019;7:205

46. Vuillermot S, Luan W, Meyer U, Eyles D. Vitamin D treatment during pregnancy prevents autism-related phenotypes in a mouse model of maternal immune activation. Mol Autism. 2017:8:1-13.

47. Kandeel WA, Meguid NA, Bjørklund G. Eid EM, Farid M, Mohamed SK, et al. Impact of clostridium bacteria in children with autism spectrum disorder and their anthropometric measurements. J Mol Neurosci. 2020;70:897-907.

48. Balestrieri E, Cipriani C, Matteucci C, Benvenuto A, Coniglio A, Argaw-Denboba $A$, et al. Children with autism spectrum disorder and their mothers share abnormal expression of selected endogenous retroviruses families and cytokines. Front Immunol. 2019;10:1-14.

49. Hviid A, Hansen JV, Frisch M, Melbye M. Measles, mumps, rubella vaccination and autism: a nationwide cohort study. Ann Intern Med. 2019;170:513-20.

50. DelaCuesta-Barrutia J, Peñagarikano O, Erdozain AM. G protein-coupled receptor heteromers as putative pharmacotherapeutic targets in autism. Front Cell Neurosci. 2020;14:588662. 